University of Nebraska - Lincoln

DigitalCommons@University of Nebraska - Lincoln

Faculty Publications of the Center on Children, Families, and the Law

Children, Families, and the Law, Center on

2014

\title{
Development and Initial Findings of an Implementation Process Measure for Child Welfare System Change
}

\author{
Mary I. Armstrong \\ University of South Florida, miarmstr@usf.edu \\ Julie S. McCrae \\ University of Denver, jmccrae@chapinhall.org \\ Michelle Graef \\ University of Nebraska-Lincoln, mgraef1@unl.edu \\ Tammy Richards \\ University of Southern Maine \\ David Lambert \\ University of Southern Maine, david.lambert@maine.edu \\ Sellowext this and fadditionalwarks wat:https://digitalcommons.unl.edu/ccflfacpub \\ Part of the Administrative Law Commons, Courts Commons, Criminology and Criminal Justice \\ Commons, Domestic and Intimate Partner Violence Commons, Family Law Commons, Family, Life \\ Course, and Society Commons, Juvenile Law Commons, Law and Psychology Commons, Law \\ Enforcement and Corrections Commons, Nonprofit Organizations Law Commons, Social Policy \\ Commons, Social Welfare Commons, and the Social Welfare Law Commons
}

Armstrong, Mary I.; McCrae, Julie S.; Graef, Michelle; Richards, Tammy; Lambert, David; Bright, Charlotte Lyn; and Sowell, Cathy, "Development and Initial Findings of an Implementation Process Measure for Child Welfare System Change" (2014). Faculty Publications of the Center on Children, Families, and the Law. 23. https://digitalcommons.unl.edu/ccflfacpub/23

This Article is brought to you for free and open access by the Children, Families, and the Law, Center on at DigitalCommons@University of Nebraska - Lincoln. It has been accepted for inclusion in Faculty Publications of the Center on Children, Families, and the Law by an authorized administrator of DigitalCommons@University of Nebraska - Lincoln. 


\section{Authors}

Mary I. Armstrong, Julie S. McCrae, Michelle Graef, Tammy Richards, David Lambert, Charlotte Lyn Bright, and Cathy Sowell 


\title{
Development and Initial Findings of an Implementation Process Measure for Child Welfare System Change
}

Mary I. Armstrong, University of South Florida, Tampa, FL, USA

Julie S. McCrae, University of Denver, Denver, CO, USA

Michelle I. Graef, University of Nebraska-Lincoln, Lincoln, NE, USA

Tammy Richards and David Lambert, University of Southern

Maine, Portland, ME, USA

Charlotte Lyn Bright, University of Maryland, Baltimore, MD, USA

Cathy Sowell, University of South Florida, Tampa, FL, USA

Corresponding author - Mary I. Armstrong, PhD, Associate Professor, Department of Child and Family Studies, University of South Florida, 13301 Bruce B. Downs Boulevard, Tampa, FL 33612, USA. E-mail: miarmstr@usf.edu

\begin{abstract}
This article describes a new measure designed to examine the process of implementation of child welfare systems change. The measure was developed to document the status of the interventions and strategies that are being implemented and the drivers that are being installed to achieve sustainable changes in systems. The measure was used in a Children's Bureau-supported national effort to assess the ongoing implementation of 24 systems-change projects in child welfare jurisdictions across the country. The article describes the process for measure development, method of administration and data collection, and quantitative and qualitative findings.
\end{abstract}

Keywords: leadership, administration and supervision, organizations/systems, policy issues

Published in Journal of Public Child Welfare, Vol. 8:94-117, 2014

DOI: $10.1080 / 15548732.2013 .873759$

Copyright (C) 2013 Taylor \& Francis Group, LLC. Used by permission.

Submitted 18 December 2012; revised 27 November 2013; accepted 6 December 2013;

published 11 February 
This article describes the development, use, and initial findings from a new measure designed to examine the process of implementation of child welfare systems change. The measure uses the framework of the National Implementation Research Network (NIRN; Fixsen, Naoom, Blase, Friedman, \& Wallace, 2005). In developing "Implementation Drivers," NIRN staff reviewed the implementation literature across a number of program areas and posited key "drivers." Each driver is a component that facilitates the implementation process; they are "dynamic and interact in interesting ways" (NIRN, n.d.). The Implementation Process Measure (IPM) uses, and adapts the NIRN framework to document the status of the interventions and strategies that are being implemented and the drivers that are being installed to achieve sustainable changes in child welfare systems. This article presents the development and results of the first 2 years of implementation efforts using quantitative and qualitative data from the process measure.

\section{Literature Review: Implementation, Organizational Change, and Child Welfare}

Many studies have demonstrated that the development and validation of evidence-based practices in mental health, substance abuse, and child welfare have not been matched by effective implementation of these practices in community settings (Aarons, 2011; Simpson, 2002). The Crossing the Quality Chasm Report (Institute of Medicine, 2001) highlighted the science to service gap in health care and illustrated that it takes approximately 17 years for a new intervention to move from randomized clinical trials to practice. Over the past decade, child welfare agencies have increasingly turned toward developing and implementing evidence-based practices. A challenge for the child welfare field is to use a framework for developing and implementing programs that incorporates evidence of what works (evidence-based) but is also broad enough to include programs that are not discrete interventions or services and may not meet evidence-based criteria, such as implementing a data system or centralized intake services. The field of implementation has proven a useful lens to pursue this.

In 2005, Fixsen and colleagues published results of a literature review that resulted in the NIRN Framework. Implementation was defined as "a specified set of activities designed to put into practice an 
activity or program of known dimensions" (Fixsen et al., 2005, p. 5). As this definition implies, one common application of implementation science is the installation of evidence-based practices. Fixsen et al. (2005) proposed that implementation occurs in chronological stages classified as exploration, installation, initial implementation, full implementation, innovation and sustainability. NIRN also identified elements of infrastructure in such efforts, called implementation drivers, which are thought to support system change. Implementation drivers include staff recruitment and selection, pre-service and in-service training, supervision and coaching, staff performance evaluation, decision support data systems, facilitative administrative supports, and supportive leadership. Other studies have highlighted the importance of organizational factors associated with implementation including the agency's readiness for change (Lehman, Greener, \& Simpson, 2002), organizational type as public or private (Aarons, Sommerfeld, \& Walrath-Greene, 2009), and relevance and fit with organizational context and structures (Rycroft-Malone et al., 2004).

Change is essential to optimal long-term organizational functioning (Cohen, 1999), but the majority of change efforts are not implemented successfully (Burns, 2004). The NIRN framework integrates some of the elements deemed important in the organizational change literature of the past several decades. The stage-based model of implementation aligns with research indicating that organizational change is a process rather than an event, and that it requires a series of steps in order to be effective (Whelan- Berry \& Somerville, 2010). Furthermore, the documented tension between leadership-driven (Kotter, 1996) and employee-focused (Armenakis \& Harris, 2009) change initiatives can be resolved via focusing on organizational, competence, and leadership elements of implementation, simultaneously.

Adopting the NIRN framework has been a priority of the Children's Bureau (CB) and is receiving increased attention in the literature. Kaye and colleagues at one of the five National Child Welfare Implementation Centers provide early descriptive examples of implementation projects and drivers (Kaye et al., 2012). James Bell Associates ( JBA) has recently reported on "Lessons Learned through the Application of Implementation Science Concepts to Discretionary Grant Programs” ( JBA, 2013). JBA found the NIRN Framework quite useful.

This research aims to increase understanding of the process of implementing systems change, specifically child welfare systems change, 
rather than outcomes of the change. We define systems change as "a shift in the structure or functional operation of the child welfare system" ( JBA, 2012). Process evaluation is useful and necessary in the relatively new and emerging field of implementation science as applied to large social service systems such as child welfare (Bhattacharyya, Reeves, \& Zwarenstein, 2009). Thus, the data collected using this measure can inform questions such as: What are the elements of systems change implementation in child welfare agencies? What are the typical stages of progression of implementation in child welfare? What are the technical assistance and organizational development needs that child welfare agencies experience as they implement systemic change?

\section{Children's Bureau's Vision for Child Welfare Implementation Centers}

Child welfare systems present a challenging environment in which to implement best or innovative practices, due to their bureaucratic complexity and the varying needs of children and families served in these systems (Aarons \& Palinkas, 2007). In recognition of the implementation challenges agencies confront, in 2008, the Children's Bureau (CB) expanded its Training and Technical Assistance (T/TA) Network by establishing five new regionally based Child Welfare Implementation Centers (ICs). The T/TA Network is designed to provide States and Tribes with information, training, technical assistance, research and consultation that support their efforts to improve child welfare systems and achieve sustainable change that will yield improved outcomes for children, youth and families. The CB funded 5-year cooperative agreements with the ICs to provide in-depth, long-term consultation to States and Tribes implementing systems change. Each IC serves the States and Tribes in two of the 10 administrative regions designated by the Administration for Children and Families.

The ICs formally solicited proposals from States and Tribes for implementation projects that identified specific problems, needs, or areas of performance that needed to be addressed systemically. Projects were required to be substantial in scope, and between 2 and 4.25 years in duration. In consultation with the $\mathrm{CB}$, proposals were selected and each IC ultimately partnered with at least three States or Tribes 
to support their implementation projects. After agreeing to a project plan, the State or Tribe and its IC entered into a mutually binding agreement. Together, the five ICs have provided coordinated, individualized, intensive technical assistance to support child welfare implementation projects in more than 25 jurisdictions.

Each implementation project was uniquely designed to address the needs of the particular jurisdiction. While they typically did not involve the implementation of evidence-based practices, these projects all constituted "systems change" in that they addressed changing how the organization approaches its work and how it operates. The following examples illustrate the broad range of systems changes these projects supported:

- Two state child welfare agencies focused intensive efforts on improving their internal organizational culture and climate, through in-depth assessments and strategic interventions such as coaching, participatory decision making, and leadership development;

- One state designed and implemented a new centralized intake for child abuse and neglect reports;

- State and tribal stakeholders within a jurisdiction worked together to build capacity to reduce disproportionality;

- A state incorporated a new safety model and assessment tools into ongoing casework practice;

- Several tribal child welfare agencies implemented practice models with defined values and standards, using tools such as business process mapping to delineate each part of the child welfare system from referrals to foster care.

One in-depth example illustrates the planning and execution of an implementation project, including the types of project activities within each of the NIRN drivers. State agency "A" requested IC assistance to design and carry out a strategic plan to implement a new state statute that codified the Indian Child Welfare Act into state law. The project's logic model included a number of short and long-term goals, such as: training CW agency staff on the expected practices; modifying approaches to Tribal child welfare agencies; incorporating the requirements into court procedures and the legal process; updating administrative rules and program standards to integrate the new 
practices; strengthening Tribal/State relationships in child welfare and the courts; increasing identification of ICWA eligible children; increasing provision of formal notice to tribes; and improving adherence to tribal placement preferences. To achieve these goals, the project focused on the following NIRN “drivers," which was accomplished through activities such as:

- Leadership: maintaining visible leadership presence over the 3.5 year duration, and to ensure necessary collaboration with key stakeholders;

- Training: for child welfare workers, supervisors, central office staff, and specialized legal training for attorneys and judges;

- Coaching: provision of on-site consultation within county child welfare offices to support the use of new practices;

- Systems Intervention: cross-system integration was required to accomplish many of the project goals, that is, leadership of multiple agencies and branches of government (e.g., Judicial and Executive branches, State, Tribal, and County-level agencies) needed to work together;

- Facilitative Administration: development of worker desk aids, review and revision of agency policies, revisions to SACWIS system to support practice expectations;

- Decision Support Data Systems: revisions to agency's CQI system to provide ongoing support towards accomplishment of ICWA goals through case file reviews.

\section{Evaluation of the Implementation Centers}

In addition to providing tailored technical assistance, resources, and support to each implementation project, the ICs are responsible for evaluating the processes and outcomes of these systems change efforts, both locally, and collectively across the IC grant cluster. Thus, there was a need to establish a common framework and measure with which to document the process of child welfare implementation. The IPM was collaboratively designed by the five ICs as a process measure that is grounded in existing implementation science frameworks, yet uniquely suited to fit the needs of child welfare systems change initiatives. 


\section{Development of the Implementation Process Measure (IPM)}

With consultation from the Children's Bureau the IC evaluators jointly determined that the NIRN framework offered the greatest potential for development of a child welfare-specific process measure. A number of existing measures and checklists to assess implementation components, drivers, and best practices were reviewed, and the NIRN core implementation components (Fixsen et al., 2009) was considered to be the strongest candidate to meet the IC's needs. IC evaluators first formally rated the fit and feasibility of each of the items comprising this measure for a sample of 14 implementation projects and determined that, while the conceptual framework of drivers and stages of implementation appeared to fit with the child welfare initiatives, the specific items comprising this (and other existing) measures did not. Items reflected an orientation towards implementing well-established evidence-based practices, in which specific protocols are known and followed. However, the implementation projects with which the ICs are involved do not typically involve evidence-based practices. The NIRN stage of "installation" did not appear to completely capture the extensive intervention design activities that many child welfare implementation projects required. In addition, a number of additional domains beyond the NIRN drivers, such as stakeholder engagement, were hypothesized as being critical to child welfare implementation initiatives. Thus, the ICs collaboratively developed a new measure, building upon NIRN's core implementation components.

The resulting IPM underwent several rounds of development, modification, pilot testing and revision; the final instrument with definitions for the drivers is included in the Appendix. The IPM is organized into four sections: 1 ) a description of project demographic characteristics, 2) a point-in-time identification of the stage of the intervention, 3) ratings and description of the level of salience and installation of each of the implementation drivers, and 4) ratings of completion of key implementation activities, accompanied by a description of barriers and facilitators encountered in conducting the activity and the strategies used to achieve each activity. The first section is completed once, at the beginning of the project, and the remaining sections are completed every 6 months for the duration of the initiative. 


\section{Summary}

In 1996, Klein and Sorra called for increased use of multiorganizational, longitudinal, quantitative studies of implementation of innovations in organizations. Unfortunately, nearly twenty years later, the science of implementation, beyond the study of implementing evidence-based practices, remains in its infancy. The development of the IPM represents a significant step towards understanding implementation of child welfare systems change initiatives across multiple organizations, innovations, and over time. Using this common measure, the process of implementing systemic change for a diverse national cohort of child welfare jurisdictions can be described.

\section{Methods}

As an exploratory study, the ICs took different approaches to developing and implementing their projects; consequently, each center adopted a somewhat different approach toward training raters and assessing inter-rater reliability when completing the implementation process measure. The typical approach was to have at least two staff who were closely involved in the project complete the measure separately. Data were entered into an online survey program (Qualtrics; www.qualtrics.com). Each IC obtained approval for the study from their University Institutional Review Board (IRB).

Data were collected using a combination of interviews with project implementation staff; review of important documents such as project plans, manuals, and other accomplishments; and group discussion between evaluators and other project staff. Not all data were collected using each of these methods, but ICs reported that most commonly, interviews were conducted with project staff $(n=14)$ and using document review $(n=13)$. Less common methods were interviews with agency stakeholders $(n=7)$, and group discussion including IC project staff $(n=8)$ and agency stakeholders $(n=3)$. Most projects were rated using more than one method $(n=18)$. 


\section{Sample}

The sample included 20 state and 4 tribal projects encompassing all areas of the 10 regionally based Children's Bureau offices in the United States. Data were collected between April, 2010 and September 2012. The sample size ranged from 19 projects (6-month rating) to 24 projects (12-month rating). The data points included in the analysis were 6-, 12-, 18-, and 24-month ratings. The number of projects changed over time for two reasons: first, because some projects began before the IPM was developed and therefore did not have 6-month ratings, and second, because projects had varying start dates and lengths (i.e., some were completed within 18 months, and others had not yet been in the field for 18 or 24 months).

Table 1 shows the types of projects implemented. Approximately one half of projects used implementation center assistance to design and implement a practice model $(46 \% ; n=11)$. Another $17 \%$ focused on implementing supervisory strategies $(n=4)$ and $8 \%$ (each) focused on implementing an existing practice model $(n=2)$ or a comprehensive technical assistance model $(n=2)$. The remaining five projects

Table 1. Project Demographics $(\mathrm{N}=22)$

\begin{tabular}{lrr} 
Characteristic & Number of projects & $\%$ \\
\hline Purpose & & \\
$\quad$ Design and implement a practice model & 10 & 45 \\
Implement an existing practice model & 3 & 14 \\
Supervisory model to support practice model & 3 & 14 \\
Comprehensive technical assistance model & 2 & 9 \\
Other $^{\text {a }}$ & & \\
Project focus & & \\
Caseworkers only & 1 & 5 \\
Supervisors only & 3 & 5 \\
Middle and upper management only & 1 & 29 \\
All except system partners & 6 & 33 \\
All & 7 & 14 \\
Other & 3 & \\
Project duration & & 5 \\
<2 years & 1 & 32 \\
2 to 2.5 years & 7 & 45 \\
3 to 3.5 years & 10 & \\
4 years & 4 & \\
\hline
\end{tabular}

a. Includes statewide centralized intake and comprehensive application of the Indian Child Welfare Act.

b. Data are missing for one project. 
$(21 \% ; n=5)$ were diverse in their goals, which included implementing statewide centralized intake application of the Indian Child Welfare Act (ICWA), and more than one type of change (e.g., supervision strategies and a practice model).

Because these were large-scale systems-change projects, all levels of the child welfare agency were typically targeted for change. Nearly onethird of initiatives (29\%) targeted all levels of the agency, apart from external system partners $(n=7)$, and one-quarter $(n=6)$ targeted all agency levels including system partners. Internal levels included upper (executive) management, middle management, supervisors, and frontline caseworkers. External partners may have included judges, families and youth, and community service providers. The remaining 11 projects focused on supervisors or middle and upper management only (21\%, $n$ $=5$ ), caseworkers only ( $4 \%, n=1)$, all agency-levels except upper management $(8 \% ; n=2)$, and "other" multilevel interventions such as with caseworkers and system partners $(13 \%, n=3)$.

The expected project length ranged from 18 to 48 months. Close to one-half $(41 \%)$ were planned for 3 to 3.5 years in duration, $38 \%$ were 2 to 2.5 years in duration, and just one initiative was less than 2 years in duration (4\%). Four projects were 4 years in duration (17\%).

At the most recent data collection point, 2 years after project start, most were in a stage of active implementation-10 projects were in initial implementation (50\%), either early initial implementation ( $n$ $=7 ; 35 \%)$ or late initial implementation $(n=3 ; 15 \%)$. Just two projects were in early full implementation (10\%), characterized by skillful and normalized integration of the change effort. The remaining projects were rated as in the early design and installation phase ( $n=$ $8 ; 40 \%)$. The most common expected end stage among projects was early full implementation ( $n=10 ; 41 \%)$, followed by late initial implementation $(n=5 ; 21 \%)$.

\section{Data Analysis}

This descriptive study used mixed methods. Quantitative data were analyzed using univariate analyses such as frequency distributions, percentages, and measures of central tendency and variability such as means and standard deviations. Bivariate Pearson chi-square analyses were conducted to explore significant differences among time periods. Quantitative analyses were conducted using SPSS software, version 19. 
Qualitative methods were used to better understand the nature and relevance of implementation drivers in child welfare system change. On the IPM, raters of these drivers were encouraged to describe in narrative form, the reasons for the salience ratings and the strategies used to employ the driver. Narrative text from the IPM was exported into Excel. Narrative descriptions were then coded and analyzed for themes, and to track changes over time in the use of the drivers. Codes were developed inductively during data analysis; the codes were then categorized into the domains of perceptions of the drivers, barriers encountered, support provided, and the influence of agency and project context. Cross validation of the codes and the coding were conducted.

\section{Results}

\section{Quantitative Results}

Mean salience ratings and the proportion of projects rating each driver as highly salient during each rating period are reported in Table 2 . Results indicate that the drivers frequently characterized as "high salience" across time points included mission, vision, and values; leadership; and stakeholder engagement. Two of these three did not increase significantly but rather remained endorsed for a high proportion of the projects; the exception is leadership, which was rated "highly salient" in $73.7 \%$ of projects at the 6 - month time point but increased, significantly, to $100 \%$ of projects in the 18 -month and 24 -month time points.

Staff selection, training, supervision and coaching, facilitative administration, and decision support data systems all increased significantly over time in their proportions of high salience ratings. Performance assessment was one of the lowest-rated elements in terms of salience at the 6 -month time point $(5.3 \%$ of projects rating it high salience). It peaked at the 18-month measurement in terms of proportion of projects with high salience $(27 \cdot 3 \%)$. Cultural responsiveness was highly salient for just $26 \%$ to $30 \%$ of projects over time. Systems intervention showed high salience in $26 \%$ to $45 \%$ of projects over time. The mean scores on the three-point salience rating ranged from a low of 1.11 (performance assessment at 6 months) to 3.00 (leadership at 18 and 24 months). Across time, drivers' salience ratings tended to increase. In other words, the majority of drivers increased in mean 
Table 2. Salience Ratings and Proportions of Projects Rated Highly Salient at Four Time Points

\begin{tabular}{|c|c|c|c|c|c|}
\hline & $\begin{array}{l}6 \text { mos. } \\
(\mathrm{n}=19) \\
\text { Mean salience } \\
(\mathrm{SD})^{\mathrm{b}} \% \text { high } \\
\text { salience }\end{array}$ & $\begin{array}{l}12 \text { mos. } \\
(\mathrm{n}=24) \\
\text { Mean salience } \\
(\mathrm{SD}) \% \text { high } \\
\text { salience }\end{array}$ & $\begin{array}{l}18 \text { mos. } \\
(\mathrm{n}=22) \\
\text { Mean salience } \\
(\mathrm{SD}) \% \text { high } \\
\text { salience }\end{array}$ & $\begin{array}{c}24 \text { mos. } \\
(\mathrm{n}=20) \\
\text { Mean salience } \\
(\mathrm{SD}) \% \text { high } \\
\text { salience }\end{array}$ & $\chi^{2}(d f)^{\mathrm{a}}$ \\
\hline $\begin{array}{l}\text { Mission, Vision, and } \\
\text { Values }\end{array}$ & $\begin{array}{l}2.58(0.61) \\
63.2 \%\end{array}$ & $\begin{array}{c}2.83(0.38) \\
83.3 \%\end{array}$ & $\begin{array}{c}2.68(0.65) \\
77.3 \%\end{array}$ & $\begin{array}{l}2.80(0.52) \\
85.0 \%\end{array}$ & $5 \cdot 76(6)$ \\
\hline Leadership & $\begin{array}{c}2.68(0.58) \\
73.7 \%\end{array}$ & $\begin{array}{c}2.83(0.48) \\
87.5 \%\end{array}$ & $\begin{array}{l}3.00(0.00) \\
100.0 \%\end{array}$ & $\begin{array}{c}3.00(0.00) \\
100.0 \%\end{array}$ & $11.33(6)^{* *}$ \\
\hline Staff Selection & $\begin{array}{c}1.37(0.60) \\
5.3 \%\end{array}$ & $\begin{array}{c}1.38(0.65) \\
8.3 \%\end{array}$ & $\begin{array}{c}1.50(0.67) \\
9.1 \%\end{array}$ & $\begin{array}{c}1.90(0.78) \\
25.0 \%\end{array}$ & $8.32(6)^{*}$ \\
\hline Training & $\begin{array}{c}1.79(0.92) \\
31.6 \%\end{array}$ & $\begin{array}{c}2.04(0.96) \\
45.8 \%\end{array}$ & $\begin{array}{c}2.36(0.79) \\
54.5 \%\end{array}$ & $\begin{array}{c}2.60(0.68) \\
70.0 \%\end{array}$ & $12.33(6)^{* *}$ \\
\hline Supervision/Coaching & $\begin{array}{c}1.63(0.83) \\
21.1 \%\end{array}$ & $\begin{array}{c}1.83(0.92) \\
33.3 \%\end{array}$ & $\begin{array}{c}2.23(0.92) \\
54.5 \%\end{array}$ & $\begin{array}{l}2.50(0.61) \\
55.0 \%\end{array}$ & $17.16(6)^{* * *}$ \\
\hline $\begin{array}{l}\text { Performance } \\
\text { Assessment }\end{array}$ & $\begin{array}{c}1.11(0.46) \\
5 \cdot 3 \%\end{array}$ & $\begin{array}{c}1.38(0.65) \\
8.3 \%\end{array}$ & $\begin{array}{c}1.68(0.89) \\
27.3 \%\end{array}$ & $\begin{array}{c}1.74(0.73) \\
15.0 \%\end{array}$ & $17.82(6)^{* * *}$ \\
\hline $\begin{array}{l}\text { Facilitative } \\
\text { Administration }\end{array}$ & $\begin{array}{c}1.74(0.73) \\
15.8 \%\end{array}$ & $\begin{array}{c}1.91(0.85) \\
30.4 \%\end{array}$ & $\begin{array}{c}2.05(0.72) \\
27.3 \%\end{array}$ & $\begin{array}{c}2.45(0.83) \\
65.0 \%\end{array}$ & $14 \cdot 44(6)^{* *}$ \\
\hline Systems Intervention & $\begin{array}{c}1.84(0.83) \\
26.3 \%\end{array}$ & $\begin{array}{c}1.83(0.94) \\
34.8 \%\end{array}$ & $\begin{array}{c}1.64(0.85) \\
22.7 \%\end{array}$ & $\begin{array}{c}2.05(0.95) \\
45.0 \%\end{array}$ & $5.09(6)$ \\
\hline $\begin{array}{l}\text { Decision Support } \\
\text { Data Syst. }\end{array}$ & $\begin{array}{c}2.00(0.94) \\
42.1 \%\end{array}$ & $\begin{array}{c}2.09(0.79) \\
34.8 \%\end{array}$ & $\begin{array}{c}2.27(0.77) \\
45.5 \%\end{array}$ & $\begin{array}{l}2.47(0.91) \\
70.0 \%\end{array}$ & $14.43(6)^{* *}$ \\
\hline $\begin{array}{l}\text { Stakeholder } \\
\text { Engagement }\end{array}$ & $\begin{array}{l}2.53(0.77) \\
68.4 \%\end{array}$ & $\begin{array}{l}2.41(0.80) \\
59.1 \%\end{array}$ & $\begin{array}{c}2.50(0.67) \\
59.1 \%\end{array}$ & $\begin{array}{c}2.79(0.42) \\
75.0 \%\end{array}$ & $5.61(6)$ \\
\hline Cultural Responsiveness & $\begin{array}{c}1.72(0.90) \\
26.3 \%\end{array}$ & $\begin{array}{c}1.74(0.87) \\
26.3 \%\end{array}$ & $\begin{array}{c}1.80(0.89) \\
30.0 \%\end{array}$ & $\begin{array}{c}1.85(0.88) \\
30.0 \%\end{array}$ & $0.62(6)$ \\
\hline
\end{tabular}

a. Exact probabilities were calculated for all chi-square values due to low expected cell counts.

b. Ratings ranged from 1 (low salience) to 3 (high salience).

${ }^{*} \mathrm{p}<.05 ;{ }^{* *} \mathrm{p}<.01 ; * * * \mathrm{p}<.001$

salience during the time projects were in the field. Exceptions to this trend were mission, vision, and values, which peaked at a mean of 2.83 at the 12-month rating, and systems intervention and stakeholder engagement, both of which fluctuated over time. The cultural responsiveness driver increased only slightly from the first to the fourth rating point, and this increase was non-significant.

Pearson chi-square analyses were conducted to determine the influence of missing data on study results. Characteristics of projects with and without missing data on salience ratings of each implementation driver were compared. Projects at the early stages of exploration and design at inception were more likely than projects beginning at a more advanced stages to be missing data on the salience of the staff selection driver $\left(\chi^{2}=15.226, d f=6, p=.019\right)$. No differences were found 
with respect to project duration or nature of the project (i.e., whether or not the project was implementing a child welfare practice model) and the salience rating as missing.

\section{Qualitative Results}

Qualitative analysis showed a number of important themes related to installation of the drivers during each time period and over time. Analysis of the qualitative data identified a number of themes related to the leadership driver. During the first 12 months of project implementation, a predominant theme was efforts on the part of IC staff to engage leadership at all levels in the project. Efforts to engage executive leadership, for example were noted. A theme that was noted throughout all phases was whether or not there were champions for a project at all levels of the organization and among external stakeholders. One approach to engaging champions was to create various types of communication channels about the project. A change in leadership was identified as a challenge in sustaining leadership engagement in any time period.

Specific to the mission, vision and values, during the early stages of implementation, IC teams heavily emphasized vision development, through such activities as engagement of leadership and internal and external stakeholders in the definition of the vision through facilitated workgroups. A theme that emerged in all time periods was the integration of vision and values in the implementation of practice models and data dashboards. Finally, challenges to vision development were identified, such as conflicting values among stakeholders, and the absence of activities to engage stakeholders.

The primary themes that emerged related to the stakeholder engagement driver in the first 12 months of implementation were efforts to engage internal and external stakeholders as well as the provision of technical assistance regarding engagement strategies. The qualitative data also revealed limited efforts to engage youth and families in this sample of projects.

Analysis of qualitative data related to the training driver indicated that during the early phases of the IPs, intervention and model selection or design had not yet been completed and therefore training had not yet been employed. As the interventions were selected or defined, projects moved to curriculum planning and development. Training 
that did occur during the early stages focused on implementation science; targeted training and coaching with individuals and groups based on needs assessments; orientation of new staff to the project; and for those projects that had completed model selection, train the trainer methods were utilized. Projects took various approaches to curriculum planning and development including: use of training committees, workgroups, advisory bodies, and staged curriculum development that led to adaptations based on trainee feedback and needs.

Challenges to employing the performance assessment driver during project implementation included having insufficient data about performance as well as the existence of jurisdiction policies that limited the conduct of staff performance assessment. High salience ratings of the performance assessment driver were related to the establishment of quality assurance and fidelity mechanisms, structures, and tools for consistent performance assessment and documentation. The integration of existing performance evaluation practices was also noted.

For some projects, low salience of the staff selection driver was associated with the use of existing staff for model implementation. For other projects, this driver became important over time and job descriptions were revised to reflect the new practice model principles. One project in particular used continual monitoring of staffing needs and schedules to develop and modify staffing plans.

One theme that emerged for the supervision/coaching driver during the first 6 months of implementation that was sustained over time was coaching by the IC staff; the coaching was conducted with various groups including executive leadership and chairs of workgroup committees. Coaching topics include selection of practice models and standards, team problem solving, and conflict resolution. For some projects, child welfare supervisors were the focus of the project as new supervision models were developed; these projects developed training and coaching plans for supervisors.

During the first 12 months the predominant theme for the facilitative administration driver was planning; planning activities included the development of new roles related to the project and the review of policies and practice to identify needed revisions. During the second year of projects, the primary theme was implementation of the new roles, rules, policies, other administrative supports, and practices.

The decision support data systems driver was described as being employed in various aspects of the projects. The scope of strategies 
related to data systems included the hiring of quality assurance and evaluation staff to carry out data system activities, the development and implementation of data dashboards and data systems, and the improvement of existing data systems. Administrative data, quality assurance findings, and stakeholder feedback were used by technical assistance and jurisdiction leadership to inform the design of the project intervention, implementation planning and strategies, inform and improve technical assistance provision, monitor fidelity and project outcomes, and improve the functioning of the jurisdiction. Technical assistance strategies included training of jurisdictions on data system models and improving data use in decision-making.

The predominant theme that emerged related to the systems intervention driver was the implementation of communication structures and protocols. Efforts were identified to develop communication strategies with workgroups, internal stakeholders, and external stakeholders such as other state agencies, parents, provider associations and counties. Structures included project advisory boards, memoranda of understanding, and newsletters. The structures were used to clarify, define and communicate roles and responsibilities, identify and resolve problems, and improve collaboration.

High salience of cultural responsiveness, the final driver discussed in this section, was noted for tribally focused implementation projects; for these IPs, cultural responsiveness was highly salient for all activities such as engagement of tribal leaders, training needs assessment, development of practice models and training curricula, assessment of policies and practices and development of data dashboards.

\section{Discussion}

The literature indicates a substantial delay between development of effective services and their implementation in real-world settings (Institute of Medicine, 2001). Furthermore, child welfare and other public social service systems lag behind medicine in their efforts to employ implementation science for more effective service delivery (Landsverk et al., 2011). The findings presented here begin to address this gap by providing descriptive, multiorganizational data on a national cohort of child welfare implementation initiatives. The modal project duration is three to three-and-one-half years. In the initial two years of 
project implementation, the most salient implementation drivers are leadership; mission, vision, and values; and stakeholder engagement. The least salient drivers during this time period are performance assessment and staff selection.

While the majority of the drivers assessed in this project come from NIRN's (Fixsen et al., 2005) conceptualization of implementation elements, two of the most salient drivers, initially and over time, are those this research team added. Mission, vision, and values indicates a shared understanding of the framework of the project among leaders, stakeholders, and agency workers. Stakeholder engagement reflects the importance of working with diverse stakeholders (such as youth and families, private providers, and other service systems) to accomplish changes in how child welfare systems operate.

Results show that leadership is a salient driver in implementation initially, and becomes even more salient over time. One study of adoption facilitators and barriers related to implementing innovative mental health practices found that expertise from an external technical assistance center was significant during the stage of full implementation, but less so during earlier stages of implementation (Seffrin, Panzano, \& Roth, 2009). In earlier stages, the study found that systemic drivers or barriers, funding, and the fit of the intervention to the agency's values and capabilities were more salient. This finding suggests that ICs' work to support leaders over time, nuanced to the implementation stage and with even greater emphasis in later implementation stages, is warranted. As the qualitative data emphasized, visible champions of practice change are important to cultivate at all levels of an organization and among external stakeholders given leadership turnover and the need to embrace system change at all organizational levels (Aarons, Hurlburt, \& Horwitz, 2011). Leaders are also important to engage because they have a direct impact on the organizational culture and climate of child welfare agencies (Glisson, Dukes, \& Green, 2006).

Results across these 24 large-scale change projects clearly indicate that projects focused on "values fit" as a primary implementation driver. The mission, vision, and values driver was highly salient in months o to 6 , and remained salient in months 18 to 24 . There are many terms associated with fit and the link between an individual or agency's values and intervention adoptability, including 
appropriateness, compatibility, relevance, and change valence (Proctor et al., 2011; Rogers, 1995; Weiner, 2009). In general, change is thought to be more likely when the change is perceived as valuable and worthwhile (Weiner, 2009). Indeed, staff in one study who did not adopt an innovative practice reported more frequently that the practice was incompatible with the organization's mission and goals compared with staff who adopted the practice (Massatti et al., 2008). Linking the current largescale changes with the overall goals of the child welfare organization and other, sometimes competing, initiatives appears to be a valuable addition to the NIRN framework.

Stakeholder engagement is also a driver added for the purpose of this data collection effort. As the data indicates, which stakeholders need to be actively engaged in a specific project at a specific time is related to the structure of the child welfare agency and its environmental context. Engaging professional stakeholders is central to addressing the complex problems families in the child welfare system face (Ross, 2009). Families and children are critical stakeholders, as well, given that acceptability of child welfare practices to clients may partially determine the success of implementation efforts (Petra \& Kohl, 2010).

Projects indicated minimal focus initially on a few drivers, including training, supervision and coaching, performance assessment, and facilitative administration. Using the NIRN framework, this characterizes the exploration stage of implementation, including identifying the nature and scope of the intervention components, and the overall approach for designing the change (Fixsen et al., 2005). In later implementation stages, functional elements that are required to carry out the change become more relevant. For example, facilitative administration (e.g., changing policies and procedures to support intervention), is rated as highly salient for just $16 \%$ of projects initially, and $65 \%$ of projects in months 18 to 24 .

The results of this study are informative about how implementation science applies to child welfare systems. In the initial stages of implementation, the child welfare systems under study focus on large-scale coordination drivers. It is important to interpret the least-salient drivers in context of the project timelines; performance assessment and selection may become more directly relevant to implementation during the later stages of multiyear projects. 


\section{Limitations}

Several limitations impact our ability to understand and use these findings. Projects were rated using a variety of methods and sources; this variability may have influenced the results. Each Implementation Center completed the ratings for its own projects, utilizing the approach that best suited its internal operations. For example, some ICs solicited input from agency stakeholders involved in project implementation prior to completing their ratings on the IPM, while other ICs completed their ratings based upon a review of extant project documentation and informal interviews with internal IC project staff. All ratings, however, were conducted by IC evaluators with considerable experience and knowledge in the areas of implementation science and child welfare. Future work will formally examine inter-rater agreement by comparing ratings on standardized "cases." As the measure continues to be used with the current cohort of projects, lessons regarding the optimum method of administration of the measure will emerge.

Findings are limited to child welfare systems change initiatives in the early exploration, design or installation phases of implementation. Description of the final stages of the implementation process will be topics for future research. At present, the IPM has demonstrated utility for delineating activities occurring during the initial stages of systems change initiatives.

Finally, all of the projects rated with the IPM were affiliated with ICs and therefore received substantial, intensive technical assistance. The ICs' focus on capacity building and understanding of relevant implementation science concepts, including the use of these specific drivers may have prompted states and tribes to engage in project activities that would not have otherwise occurred. Therefore, it is unknown to what extent these findings may generalize to states/tribes pursuing child welfare systems change initiatives without this type of technical assistance.

\section{Conclusions}

Measurement is a key component of implementation science (Fixsen et al., 2010). Measurement of the implementation process is important to inform the field about strategies that may be appropriate for 
public child welfare agencies undertaking systemic change. The IPM has been developed to identify and understand the stages and drivers that are most salient in child welfare implementation.

The identification of the mission and vision driver as among the most salient in these projects supports its inclusion in future implementation models within child welfare systems. In the early stages of implementation, our analysis suggests it is particularly helpful for agencies to align strategic initiatives and efforts. "Ongoing articulation by top leadership of agency mission, values and goals provides structure and engagement through interactions with managers, supervisors and line staff" (Claiborne et al., 2011, p. 2101).

The relative paucity of empirical evidence on effective implementation in child welfare systems, coupled with the increased accountability of child welfare agencies for positive outcomes, suggests a need for a clearer understanding of implementation principles as they apply in these settings. Adaptation of the NIRN (Fixsen et al., 2005) framework is one step toward advancing our understanding of implementation science in child welfare.

\section{Implications}

The study cannot draw conclusions about whether having IC technical assistance led to the success of child welfare systems change. However, the study implies that there are certain factors that change agents can highlight when working with agencies to achieve such change. First, the work tends to center on bringing stakeholders together around establishing a common framework, mission and goals. This may include having multiple workgroups that focus on particular aspects of the change. Attention should be paid to communicating about the work, not only what it is (substance) and how it will be implemented, but also how the diffusion will occur over time and impact staff. Initially, many parts of the innovation will be unclear; however, change agents can work with the agency to define the "hard core"the key goals and components of the innovation-and acknowledge the soft periphery (the elements that will be needed to put it into place; Greenhalgh, Robert, Macfarlane, \& Kyriakidou, 2004). This will help leaders communicate about the work confidently and consistently, increasing the likelihood of adoption. 
The role of leadership is evident, and in early stages, the technical assistance should focus on how leaders will be mobilized throughout the process. What should be their level of participation? What kinds of leaders are needed? What is the current agency leadership style? Leaders may want additional training and assistance, and should be prepared to be persistent when promoting the project with stakeholders and staff. Staff surveys can help the agency become more transparent about its strengths and challenges in organizational functioning.

Finally, training supplemented by coaching appears to be a necessary part of any new initiative. The IC projects used multi-level, staged training and coaching models. For example, training state-level staff to be implementation coaches in local counties, and then training countylevel staff to coach the next round of counties. In summary, the practice of organizational change in child welfare agencies is progressing to be more planful and cognizant of implementation science. Common elements to implementation were found in this study that agencies can use for large-scale change efforts.

\section{References}

Aarons, G. A., Hurlburt, M., \& Horwitz, S. M. (2011). Advancing a conceptual model of evidence-based practice implementation in public service sectors. Administration and Policy in Mental Health and Mental Health Services Research, 38, 4-23.

Aarons, G. A., \& Palinkas, L. A. (2007). Implementation of evidence-based practice in child welfare: Service provider perspectives. Administration and Policy in Mental Health and Mental Health Services Research, 34, 411-419.

Aarons, G. A., Sommerfeld, D. H., \& Walrath-Greene, C. M. (2009). Evidencebased practice implementation: The impact of public versus private sector organization type on organizational support, provider attitudes, and adoption of evidence- based practice. Implementation Science, 4(1), 1-13.

Armenakis, A. A., \& Harris, S. G. (2009). Reflections: Our journey in organizational change research and practice. Journal of Change Management, 9(2), 127-142.

Bhattacharyya, O., Reeves, S., \& Zwarenstein, M. (2009). What is implementation research? Rationale, concepts, and practices. Research on Social Work Practice, 19, 491-502.

Burns, B. (2004). Managing change. Upper Saddle River, NJ: Prentice Hall. Claiborne, N., Auerbach, C., Lawrence, C., Liu, J., McGowan, B.G., Fernendes, G., \& Magnano, J. (2011). Child welfare agency climate influence on worker commitment. Children and Youth Services Review, 33, 2096-2102. 
Cohen, M. (1999). Commentary on the organization science special issue on complexity. Organization Science, 10(3), 373-376.

Fixsen, D., Blase, K., Naoom, S., \& Van Dyke, M. (2010, October). Stage-based measures of implementation components. Chapel Hill, NC: University of North Carolina, Frank Porter Graham Child Development Institute, National Implementation Research Network.

Fixsen, D. L., Blase, K. A., Naoom, S. F., \& Wallace, F. (2009). Core implementation components. Research on Social Work Practice, 19, 531-540.

Fixsen, D. L., Naoom, S. F., Blase, K. A., Friedman, R. M., \& Wallace, F. (2005). Implementation research: A synthesis of the literature. Tampa, FL: University of South Florida, Louis de la Parte Florida Mental Health Institute, The National Implementation Research Network (OFMHI Publication \#231).

Glisson, C., Dukes, D., \& Green, P. (2006). The effects of the ARC organizational intervention on caseworker turnover, climate, and culture in children's service systems. Child Abuse and Neglect, 30, 849-854.

Greenhalgh, T., Robert, G., Macfarlane, P. B., \& Kyriakidou, O. (2004). Diffusion of innovations in service organizations: Systematic review and recommendations. Milbank Quarterly, 82(4), 581-629.

Institute of Medicine (2001). Crossing the quality chasm: A new health system for the 21st century. Washington, DC: National Academy Press.

James Bell Associates ( JBA). (2012). Systems change, capacity building, and practice improvement. Arlington, VA.

James Bell Associates ( JBA). (2013). Lessons learned through the application of implementation science concepts to Children's Bureau discretionary grant programs. Arlington, VA.

Kaye, S., DePanfilis, D., Bright, C., \& Fischer, C. (2012). Applying implementation drivers to child welfare systems change: Examples from the field. Journal of Public Child Welfare, 6(4), 513-530.

Klein, K. J., \& Sorra, J. S. (1996). The challenge of innovation implementation. Academy of Management Review, 21, 1055-1080.

Kotter, J. (1996). Leading change. Boston, MA: Harvard Business School Press.

Landsverk, J., Brown, C. H., Reutz, J. R., Palinkas, L., \& Horwitz, S. M. (2011). Design elements in implementation research: A structured review of child welfare and child mental health studies. Administration and Policy in Mental Health and Mental Health Services Research, 38, 54-63.

Lehman, W. E., Greener, J. M., \& Simpson, D. D. (2002). Assessing organizational readiness for change. Journal of Substance Abuse Treatment, 22, 197-209.

Massatti, R. R., Sweeney, H. A., Panzano, P. C., \& Roth, D. (2008). The de-adoption of innovative mental health practices (IMHP): Why organizations choose not to sustain an IMHP. Administration and Policy in Mental Health, 35, 50-65.

National Implementation Research Network. (n.d.). Implementation drivers. Retrieved from http://nirn.fpg.unc.edu/learn-implementation/ implementation-drivers

Petra, M., \& Kohl, P. (2010). Pathways Triple P and the child welfare system: A promising fit. Children and Youth Services Review, 32, 611-618. 
Proctor, E., Silmere, H., Raghavan, R., Hovmand, P., Aarons, G., Bunger, A., Griffey, R., \& Hensley, M. (2011). Outcomes for implementation research: Conceptual distinctions, measurement challenges, and research agenda. Administration and Policy in Mental Health, 38, 65-76.

Rogers, E. M. (1995). Diffusion of innovations (4th ed.). New York, NY: Free Press.

Ross, T. (2009). Child welfare: The challenges of collaboration. Washington, DC: Urban Institute.

Rycroft-Malone, J., Harvey, G., Seers, K., Kitson, A., McCormack, B., \& Titchen, A. (2004). An exploration of the factors that influence the implementation of evidence into practice. Issues in Clinical Nursing, 1, 913-924.

Seffrin, B., Panzano, P.C., \& Roth, D. (2009). What gets noticed: How barrier and facilitator perceptions relate to the adoption and implementation of innovative mental health practices. Community Mental Health Journal, 45, 260-269.

Simpson, D. D. (2002). A conceptual framework for transferring research into practice. Journal of Substance Abuse Treatment, 22, 171-182.

Weiner, B. J. (2009). A theory of organizational readiness for change. Implementation Science, 4, 67.

Whelan-Berry, K. S., \& Somerville, K. A. (2010). Linking change drivers and the organizational change process: A review and synthesis. Journal of Change Management, 10(2), 175-193.

\section{Contributors}

Mary I. Armstrong, PhD, is an Associate Professor in the Department of Child and Family Studies at the University of South Florida in Tampa, FL.

Julie S. McCrae, MSW, PhD, is a Research Associate for the Butler Institute for Families in the Graduate School of Social Work at the University of Denver in Denver, CO.

Michelle I. Graef, PhD, is a Research Associate Professor for the Center on Children, Families \& the Law at the University of Nebraska-Lincoln in Lincoln, NE.

Tammy Richards, MEd, is a Research Associate in the Muskie School of Public Service at the University of Southern Maine in Portland, ME.

David Lambert, PhD, is an Associate Research Professor in the Muskie School of Public Service at the University of Southern Maine in Portland, ME.

Charlotte Lyn Bright, MSW, PhD, is an Assistant Professor at the University of Maryland School of Social Work in Baltimore, MD.

Cathy Sowell, LCSW, is a Social \& Behavioral Researcher in the Department of Child and Family Studies at the University of South Florida in Tampa, FL. 


\section{Appendix: Implementation Process Measure}

\section{Implementation Center \\ Implementation Process Measure (IPM)}

This measure is intended to track the processes that state, county, and tribal jurisdictions use to implement systems changes during Implementation Projects. Project evaluators should complete this instrument in collaboration with implementation staff and staff from the jurisdiction as needed every 6 months.

\section{Implementation Project Demographics}

(This section is to be completed once, at beginning of project)

1. Implementation Project ID:

2. Intervention:

3. Identify the nature of the project: (check all that apply)

_ Design and implementation of a child welfare practice model

_ Implementation of an existing child welfare practice model

Other:

4. Primary focus of practice change: (check all that apply)

_ Upper/Executive Management Mid Management

_ Supervisors

_ System partners

Caseworkers

Other:

5. At initial proposal, this project was in what implementation stage?

\begin{tabular}{ll} 
Early Exploration & - Late Exploration \\
Early Design/Installation & Late Design/Installation \\
Early Initial Implementation & - Late Initial Implementation \\
\hline Early Full Implementation & - Late Full Implementation
\end{tabular}

6. Please describe any variation in geography, project components or other information to provide context for the initial stage.

7. What was the proposed duration of this project? months

8. What was the approved duration of this project? months

9. What implementation stage is this project/intervention expected to reach?

\begin{tabular}{ll}
- Early Exploration & Late Exploration \\
$\begin{array}{l}\text { Early Design/Installation } \\
\text { Early Initial Implementation }\end{array}$ & Late Design/Installation \\
\hline & - Late Initial Implementation \\
\hline
\end{tabular}

10. Please describe any variation in geography, project components or other information to provide context for the expected stage.

11. What is the geographic scope of this implementation project?
_ State wide Tribal wide County/regional Other:

12. Describe the programmatic scope of this project. 


\title{
Implementation Process Ratings
}

(To be completed every 6 months)

1. Project ID:

2. Date of this rating:

3. Which time period are you rating (select one)?

o-6 months 12-18 months 24-30 months 36-42 months 6-12 months 18-24 months 30-36 months 42-48 months

4. What method of administration was used to complete the IPM during this rating period? (check all that apply)

_ Document review Interviews with IC project staff (In completion of other IC specific survey/process) Interviews with IC project jurisdiction stakeholders (In completion of other IC specific survey/process) Group discussion with evaluator and at least one IC project staff.

_ Group discussion with evaluator and at least one IC project jurisdiction stakeholder

5. What stage is the project/intervention in at the time of this rating?

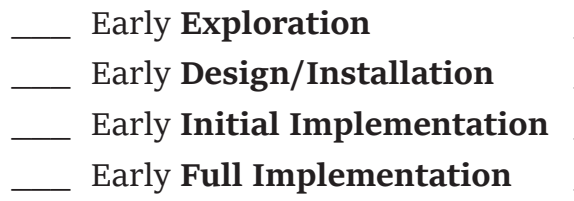

\author{
Late Exploration \\ Late Design/Installation \\ Late Initial Implementation \\ Late Full Implementation
}

6. Please describe changes in context that might impact the project since the previous rating period.

\section{Salience and Installation of Implementation Drivers}

(To be completed every 6 months)

For the 6 month review period, provide two ratings for each driver: the salience (i.e., importance or relevance) of the driver, and the installation (i.e., the extent to which the driver is in place), according to the following scales. Then describe why/ how the driver is important and what technical assistance (TA) and implementation strategies/activities have been conducted to install or employ the driver.

\section{Salience (Importance/Relevance) Rating Scale:}

(1) Low salience-the driver had little or no importance/relevance during this period, (2) Moderate salience-the driver had some importance/relevance during this period, or there was discussion or planning to address this driver in the future, or (3) High salience-the driver had substantial importance/ relevance during this reporting and a significant amount of effort occurred to leverage the driver to support implementation. 


\section{Installation Rating Scale:}

(o) NA for drivers with low salience during this reporting period, (1) Not Yet Initiated, (2) Initiated or Partially in Place, or (3) Fully in Place.

\begin{tabular}{|l|l|l|l|}
\hline Implementation Driver & $\begin{array}{l}\text { Salience } \\
\text { Rating } \\
\text { (Importance/ } \\
\text { Relevance) }\end{array}$ & $\begin{array}{l}\text { Installation } \\
\text { Rating }\end{array}$ & $\begin{array}{l}\text { Description of why/how the driver } \\
\text { is salient and the TA and } \\
\text { implementation strategies/activities } \\
\text { conducted during this period to } \\
\text { install or employ each driver. }\end{array}$ \\
\hline Shared vision, values, and mission & & & \\
\hline Leadership & & & \\
\hline Staff selection & & & \\
\hline Training & & & \\
\hline Supervision/Coaching & & & \\
\hline Performance assessment & & & \\
\hline Facilitative administration & & & \\
\hline Systems intervention & & & \\
\hline Decision support data systems & & & \\
\hline Stakeholder engagement & & & \\
\hline Cultural responsiveness & & & \\
\hline
\end{tabular}




\section{Completion of Key Implementation Activities}

(To be completed every 6 months)

For each activity, indicate whether it was: (1) Not Yet Initiated, (2) Initiated or Partially in Place, (3) Fully in Place, during the previous 6 month period. Use NA for any Not Applicable items. Use the notes to clarify or provide more information about the activity.

\begin{tabular}{|c|c|c|}
\hline Implementation Activity & Rating & $\begin{array}{l}\text { Description of barriers and } \\
\text { facilitators in conducting the } \\
\text { activity and strategies used to } \\
\text { achieve the goals of the } \\
\text { activity. }\end{array}$ \\
\hline \multicolumn{3}{|l|}{$\begin{array}{l}\text { 1. Establish leadership/workgroup to guide and oversee project } \\
\text { design and/or implementation. }\end{array}$} \\
\hline \multicolumn{3}{|l|}{$\begin{array}{l}\text { 2. Develop stakeholder engagement strategies to inform and } \\
\text { involve key stakeholders in each phase of implementation. } \\
\text { (e.g. activities, participants, timeline, benefits, risks) }\end{array}$} \\
\hline \multicolumn{3}{|l|}{$\begin{array}{l}\text { 3. Review, identify, and discuss to what extent the project addresses: } \\
\text { a. Need in agency, setting (e.g. socially significant issues, parent/ } \\
\text { community perceptions of need, data) }\end{array}$} \\
\hline \multicolumn{3}{|l|}{$\begin{array}{l}\text { b. Fit with current initiatives (e.g. Initiatives, agency } \\
\text { priorities, organizational structures, community values) }\end{array}$} \\
\hline \multicolumn{3}{|l|}{$\begin{array}{l}\text { c. Resources (e.g. staffing training, data systems, coaching/ } \\
\text { supervision, administrative/system supports needed, time) }\end{array}$} \\
\hline \multicolumn{3}{|l|}{$\begin{array}{l}\text { d. Strength of evidence of the intervention (e.g. outcomes, } \\
\text { fidelity, cost, target population) }\end{array}$} \\
\hline \multicolumn{3}{|l|}{ e. Readiness (e.g. staff have skills, abilities, desire for change) } \\
\hline \multicolumn{3}{|l|}{$\begin{array}{l}\text { 4. Consultation with experts and literature regarding proposed } \\
\text { design/adaptations and likely impact on outcomes }\end{array}$} \\
\hline \multicolumn{3}{|l|}{$\begin{array}{l}\text { 5. Intervention is developed and precisely defined (e.g. } \\
\text { vision is clearly articulated, system impacts/outcomes are } \\
\text { clearly defined, logic model is developed, initial work plan } \\
\text { is developed) }\end{array}$} \\
\hline \multicolumn{3}{|l|}{$\begin{array}{l}\text { 6. Intervention components and new practices are } \\
\text { operationalized and fidelity criteria are identified }\end{array}$} \\
\hline \multicolumn{3}{|l|}{$\begin{array}{l}\text { 7. Intervention outcomes are defined and evaluation plan } \\
\text { is developed }\end{array}$} \\
\hline \multicolumn{3}{|l|}{ 8. Develop implementation plans and strategies } \\
\hline \multicolumn{3}{|l|}{$\begin{array}{l}\text { 9. Adaptive challenges are being identified and problem solving } \\
\text { is occurring on a consistent basis. (e.g. weekly } \\
\text { implementation team meetings to identify issues, create plans, } \\
\text { review results of past problem-solving efforts, } \\
\text { forward issues to key leaders and stakeholders as appropriate) }\end{array}$} \\
\hline \multicolumn{3}{|l|}{$\begin{array}{l}\text { 10. Improvement processes are employed to address issues } \\
\text { through the use of data, development of plans, monitoring } \\
\text { of plan execution and assessment of results. }\end{array}$} \\
\hline $\begin{array}{l}\text { 11. Fidelity data, outcomes data, feedback from internal and external } \\
\text { stakeholders analyzed to determine which modifications need to } \\
\text { be made to the intervention. }\end{array}$ & & \\
\hline
\end{tabular}




\section{Definitions of Implementation Stages}

\section{Exploration Stage}

- Actively considering a systems change; engaged in identifying the need for the change, the nature and scope of the intervention components of the change, the degree of awareness and support for the change, and the overall approach for designing the systems change.

\section{Design \& Installation Stage}

- Actively preparing for implementation of the systems change project; including detailed design of both the intervention components and plans for their implementation, including structural and functional systems changes, and assembling the resources necessary to launch the program.

\section{Initial Implementation Stage}

- Actively engaged in learning how to do the systems change project interventions, and how to support the ongoing activities of the interventions. First steps towards monitoring and supporting the use of new skills, practices, tools and strategies necessary to sustain the systems change.

\section{Full Implementation Stage}

- Actively working to make full use of the systems change interventions as part of typical functioning. New learning becomes integrated into practitioner, organizational, and community practices, policies and procedures. Staff members become skillful and the procedures and processes become normalized.

\section{Definitions of Implementation Drivers}

\section{Shared Vision, Values, and Mission}

- There is a shared understanding of the vision, mission, and values among leaders and stakeholders that will promote change and provide a framework for the project.

\section{Leadership}

- There is buy in, leadership and champions for change at all levels of the organization and system. Clear and frequent communication channels exist between leadership, staff and stakeholders.

\section{Staff Selection}

- Job descriptions, recruitment strategies, and hiring procedures are aligned to identify and hire staff with the knowledge, skills, and abilities to support the new model. New staff or existing staff are selected to carry out the design and/or implementation of the project/intervention. 


\section{Training}

- Staff at all levels are provided training on the intervention and appropriate resources are allocated to support training, technical assistance and expertise needed to support implementation.

\section{Supervision/Coaching}

- Supervision and coaching plans are developed and implemented for staff at all levels to support the integration of new skills related to the intervention.

\section{Performance Assessment}

- A mechanism is in place and is being utilized to assess the performance of staff carrying out the intervention.

\section{Facilitative Administration}

- Practices, policies, and procedures have been added or changed as needed to support and be aligned with implementation of the project/intervention. Organizational structures and roles have been changed as needed to support implementation.

\section{Systems Intervention}

- System wide structures have been added or adapted as needed to support implementation and shared accountability.

\section{Decision Support Data Systems}

- Data are used to inform the development and design of the intervention. Data collection and reporting systems are in place and being utilized to monitor fidelity and outcomes of the project/intervention. Quality assurance/ improvement mechanisms are in place and being utilized to assess and improve the functioning of the organization as it relates to the intervention.

\section{Stakeholder Engagement}

- Internal and external stakeholders including caregivers, families and youth are actively and consistently involved in planning, implementation, evaluation, and decision making ensuring the system change meets their needs.

\section{Cultural Responsiveness}

- Interventions are selected that are culturally-sensitive and appropriate for the target population. Emphasis is placed on cultural sensitivity/competency of staff at all levels and use of culturally-appropriate services. 